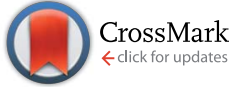

Cite this: RSC Adv., 2017, 7, 6691

Received 13th December 2016 Accepted 11th January 2017

DOI: 10.1039/c6ra28131a

www.rsc.org/advances

\section{Effective removal of chemical warfare agent simulants using water stable metal-organic frameworks: mechanistic study and structure- property correlation $\uparrow$}

\author{
P. Asha, Mekhola Sinha and Sukhendu Mandal*
}

Removal of chemical warfare agents (CWAs), which are deadly poisonous chemicals which bind to the neurotransmitter acetylcholine esterase or form painful blisters in the exposed parts of the body, affecting the nervous system of humans and other living beings, is a primary concern in every aspect. Here we present the adsorptive removal of two of the CWA simulants, 2-chloro ethyl ethyl sulfide (2CEES) and/or its hydrolysis products and dimethyl methyl phosphonate (DMMP) from aqueous medium using two Zr-based metal-organic frameworks (MOFs), NU-1000 and UiO-67, respectively. We have studied the kinetics of this adsorption process using ICP-AES data. The data show that the kinetics follows a pseudo-second-order model and the interactions between adsorbates and adsorbents are chemical in nature. DRIFT spectral data provide evidence of the chemical interactions. We have correlated this adsorption behavior with the corresponding crystal structures.

\section{Introduction}

The recent threat of terrorist attacks with toxic chemical warfare agents (CWAs) drives the research for designing new materials to remove them under ambient conditions. Among all the classes of chemical weapons, sulfur mustard and nerve agents are the most common., ${ }^{1,2}$ Sulfur mustard, also known as mustard gas or HD is a notorious blistering agent that was used in World War I. Nerve agents are organophosphorus compounds containing $\mathrm{P}-\mathrm{X}$ bonds ( $\mathrm{X}=\mathrm{F}, \mathrm{CN}, \mathrm{SR}$, etc.), that inhibit the key enzyme acetylcholine esterase involved in neuronal signaling. Despite the international ban on their use, sulfur mustard gas or nerve agents are still a chemical weapon of choice in modern warfare. It is vital to develop methods or materials to detoxify or remove the chemical warfare agents., Sulfur mustard can be detoxified by dehydrohalogenation, hydrolysis or oxidation. Dehydrohalogenation and hydrolysis suffer difficulties due to slow kinetics, the low solubility of sulfur mustard in water and the formation of toxic products. The oxidation process needs particular attention because excess oxidation of sulfoxide produces another blistering agent, sulfone. The detoxification of nerve agents by hydrolysis

School of Chemistry, Indian Institute of Science Education and Research, Thiruvananthapuram, Kerala-695016, India.E-mail: sukhendu@iisertvm.ac.in

$\uparrow$ Electronic supplementary information (ESI) available: Details of EDX studies, NMR plots, figures of PXRD for both the MOFs before and after adsorption, SEM images of the MOFs, BET surface area and pore diameter measurements, TGA plots for NU-1000 and UiO-67, GC-MS plots of 2-CEES and DMMP, table containing ICP-AES data are included. See DOI: 10.1039/c6ra28131a produces less toxic chemical products, but the rate is very low. Regarding real life application, adsorption technique outweighs all other methods due to simplicity and efficiency. Adsorption of the CWA simulants and/or the products formed after hydrolysis or oxidation demands high attention.

Metal complexes, heterogeneous catalysts, and nanomaterials have been shown to use in detecting ${ }^{5-9}$ and detoxifying $^{\mathbf{1 0 - 2 5}}$ the chemical warfare agents. However, in most of these cases, the material is not stable in water and the activity is irreversibly inhibited by the reaction products. ${ }^{26}$ In this context, water-stable thermally robust metal-organic frameworks (MOFs) are promising candidates for the detoxification or removal of CWAs. ${ }^{27-29}$ Several factors like the high surface area and specific active adsorption sites of MOFs are playing roles together for the efficient adsorption of CWAs. It shows that $\mathrm{Zr}^{\mathrm{IV}}$ containing MOFs could detoxify the CWAs either through hydrolysis or by partial oxidation. ${ }^{30-35,38-40}$

Due to the high level of toxicity of the life-threatening chemical warfare agents, simulants which structurally resemble CWAs but less malignant are in common use for the laboratory studies. 2-CEES is the simulant of sulfur mustard gas and DMMP is the simulant of sarin (Fig. 1). 2-CEES is partly soluble in water but will hydrolyze to give a variety of products, most of them are toxic in nature. ${ }^{36-38}$ DMMP is completely soluble in water.

Among several methods to remove toxic chemicals, adsorptive removal is significant, due to its simple operation and cost effectiveness. ${ }^{34,41-49}$ There are few reports where MOFs are used for this purpose, but the mechanism of these types of 
<smiles>ClCCSCCCl</smiles><smiles>CCSCCCl</smiles>

Sulfur mustard<smiles>CC(C)O[P+](C)(=O)F</smiles>

Sarin

\section{2-CEES}

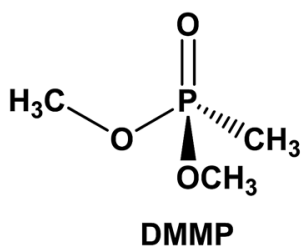

Fig. 1 Schematic of the CWAs and their simulants.

adsorption processes is still ambiguous. In the present work, we have used Zr-based MOFs (NU-1000 and UiO-67) for the efficient adsorption and removal of CWA simulants, (or namely) 2-CEES and DMMP from the aqueous medium. Adsorption capacities of CWA simulants were very high, which may be due to the large surface area and the presence of plenty of $\mathrm{Zr}-\mathrm{OH}$ groups in the nodes of these MOFs. We have studied the kinetics of the adsorption process using ICP-AES data. The data show that it follows the pseudo-second-order model and the interactions between adsorbates and adsorbents are chemical in nature. DRIFT spectral data support the evidence of chemical interactions. We assumed that the rate determining step would be the valence forces through the sharing or exchange of electrons between adsorbates and adsorbents. We have correlated this adsorption behavior with the corresponding crystal structures.

\section{Materials and methods}

All the chemicals were purchased from Sigma-Aldrich and used as such. The reported solvothermal methods demonstrate the synthesis of NU-1000, and UiO-67. ${ }^{50-52}$ Acid treatment of the corresponding MOFs has been carried out before the vacuum activation. The NU-1000 MOF is activated overnight under dynamic vacuum at $120{ }^{\circ} \mathrm{C}$ until it reaches a vacuum level of $\leq 0.002 \mathrm{mmHg} \mathrm{min}^{-1}$, as reported in the literature. UiO-67 is activated at $100^{\circ} \mathrm{C}$ under vacuum for $24 \mathrm{~h}$. Activated MOFs were kept in a desiccator before the adsorption studies.

\section{ICP-AES study}

The stock solutions of CWA simulants were prepared by dissolving calculated amounts of 2-CEES and DMMP in de-ionized water. One $\mathrm{mL}$ of the stock solution has been added to two series of different vials with $3 \mathrm{mg}$ of NU-1000 and UiO-67 respectively. All the vials were kept for shaking just after the addition of simulant solutions to the MOFs without any time delay. At different time intervals - from $15 \mathrm{~min}$ to $8.5 \mathrm{~h}$ - each vial was taken, centrifuged and $500 \mu \mathrm{L}$ of the supernatant is collected and diluted with $4.5 \mathrm{~mL}$ of de-ionized water. The diluted supernatant is examined for the concentration of the element sulfur in 2-CEES solution, phosphorus in DMMP solution and zirconium in both by inductively coupled plasmaatomic emission spectroscopy (ICP-AES). $500 \mu \mathrm{L}$ of the stock

solution is diluted with $4.5 \mathrm{~mL}$ of de-ionized water and studied as standard. Control experiments were also done for both the cases without using MOFs.

\section{Recyclability}

We have studied the process of adsorption using ICP-AES by measuring the concentration of sulfur and phosphorus in the supernatant during adsorption process in the case of 2-CEES and DMMP, respectively, and compared it with the element concentrations in the standard solution (Table S1 $\dagger$ ). After the adsorption studies, the MOFs have been washed with water and acetone, three times each. NU-1000 was found to be stable, hence used for further adsorption studies (Table S2 $\dagger$ ). But UiO67 has found degraded after washing (Fig. S9 \& S10†). It was clear that UiO-67 was stable during the process of adsorption since no zirconium has leached out from the MOF structure as per the ICP-AES result, but is losing its crystallinity only during the washing process (Table S1†).

\section{${ }^{31} \mathrm{P}$ and ${ }^{1} \mathrm{H}$ NMR}

${ }^{1} \mathrm{H}$ NMR study was performed for 2-CEES and ${ }^{31} \mathrm{P}$ NMR for DMMP. In the case of 2-CEES, the complexity of the spectrum which was entirely different from the ${ }^{1} \mathrm{H}$ NMR spectrum of 2CEES in chloroform - shows the formation of some hydrolysis products(C) which are difficult to distinguish. The intensity of some product peaks is found to vary up and down after 30 minutes. After one hour of contact between the CWA simulant solutions and the MOFs, the intensity of every peak started decreasing. So it was evident that the 2-CEES and/or the hydrolysis products started adsorbing onto the MOFs (Fig. S1 and $\mathrm{S} 2 \dagger$ ).

In the case of DMMP, we could not find any new peaks for the suspected hydrolysis and/or oxidation products in both the cases. But the intensity of the ${ }^{31} \mathrm{P}$ peak was observed to decrease with time which shows the diminishing concentration of DMMP in water with time and hence the adsorptive removal of the same by the MOFs (Fig. S3†).

\section{Results and discussion}

\section{Characterization of NU-1000 and UiO-67}

The reported procedures were adopted to synthesize the MOFs. The purity of the samples was confirmed by the PXRD data (Fig. S4†). SEM images reveal the discrete particles of both the MOFs where NU-1000, which has a size in micrometer scale and UiO-67 are found to be uniform in shape and size (Fig. $55 \dagger$ ). The surface areas have been measured using $\mathrm{N}_{2}$ adsorption study which gave similar results as reported in the literature (Fig. S6 $†$ ). NU-1000 has wide mesoporous channels ( $31 \AA$ A), and UiO-67 has octahedral $(16 \AA)$ and tetrahedral $(14 \AA)$ cages. TGA data show that framework of both NU-1000 and UiO-67 are exceptionally stable up to $500{ }^{\circ} \mathrm{C}$ (Fig. S7†).

\section{Structural description}

NU-1000 is built up of eight connected $\mathrm{Zr}_{6}\left(\mu_{3}-\mathrm{O}\right)_{4}\left(\mu_{3}-\mathrm{OH}\right)_{4}\left(\mathrm{H}_{2}-\right.$ $\mathrm{O})_{4}(\mathrm{OH})_{4}$ nodes and tetra topic $1,3,6,8(p$-benzoate $)$ pyrene 
$\left(\mathrm{TBAPy}^{4-}\right)$ linkers. UiO-67 composed of 12-connected $\mathrm{Zr}_{6} \mathrm{O}_{4}(\mathrm{OH})_{4}$ clusters as nodes and linear $4,4^{\prime}$-biphenyl dicarboxylic acid (BPDC) ligand. It possesses a face-centered cubic arrangement of the $\mathrm{Zr}_{6}$ clusters (Fig. S8 $\dagger$ ). Both NU-1000 and UiO-67 contain free and bridging $\mathrm{OH}$ and $\mathrm{H}_{2} \mathrm{O}$ groups which may be responsible for the interactions with the adsorbates.

\section{SEM-EDX study}

SEM-EDX was carried out before and after adsorption studies (sample recovered after washing) and results show that phosphorus and sulfur were adsorbed and it can be easily removed after washing (Fig. S11-S14†).

\section{DRIFT spectroscopic study}

The DRIFT-IR spectra of the MOFs NU-1000 and UiO-67 have been collected after centrifuging it from the CWA simulant solutions (Fig. 2). When 2-CEES was adsorbed on NU-1000, a new peak has been observed at $1661 \mathrm{~cm}^{-1}$ which may have formed due to the interaction between the sulfur group of 2CEES and the zirconium nodes of the MOF (Fig. 2a). Another two peaks at $1255 \mathrm{~cm}^{-1}$ and $1049 \mathrm{~cm}^{-1}$ may correspond to the pure IR peaks of 2-CEES at $1267 \mathrm{~cm}^{-1}$ and $1058 \mathrm{~cm}^{-1}$, respectively. The red-shift of the peaks may be due to the weakening of the bonds in 2-CEES on its interaction with the MOF.

When DMMP was adsorbed on NU-1000 (Fig. 2b), seven new peaks were observed. Two peaks at $1658 \mathrm{~cm}^{-1}$ and $1228 \mathrm{~cm}^{-1}$ are new and are not belongs to the pure DMMP IR peaks. As in the case of 2-CEES with NU-1000, this may also have generated due to the chemical bond that formed between phosphorus and the zirconium node. The other five peaks which are at 2966 $\mathrm{cm}^{-1}, 2855 \mathrm{~cm}^{-1}, 1317 \mathrm{~cm}^{-1}, 917 \mathrm{~cm}^{-1}$ and $828 \mathrm{~cm}^{-1}$ correspond to the DMMP peaks at $2974 \mathrm{~cm}^{-1}, 2858 \mathrm{~cm}^{-1}, 1317 \mathrm{~cm}^{-1}$, $920 \mathrm{~cm}^{-1}$ and $829 \mathrm{~cm}^{-1}$, respectively. The formation of bonds to
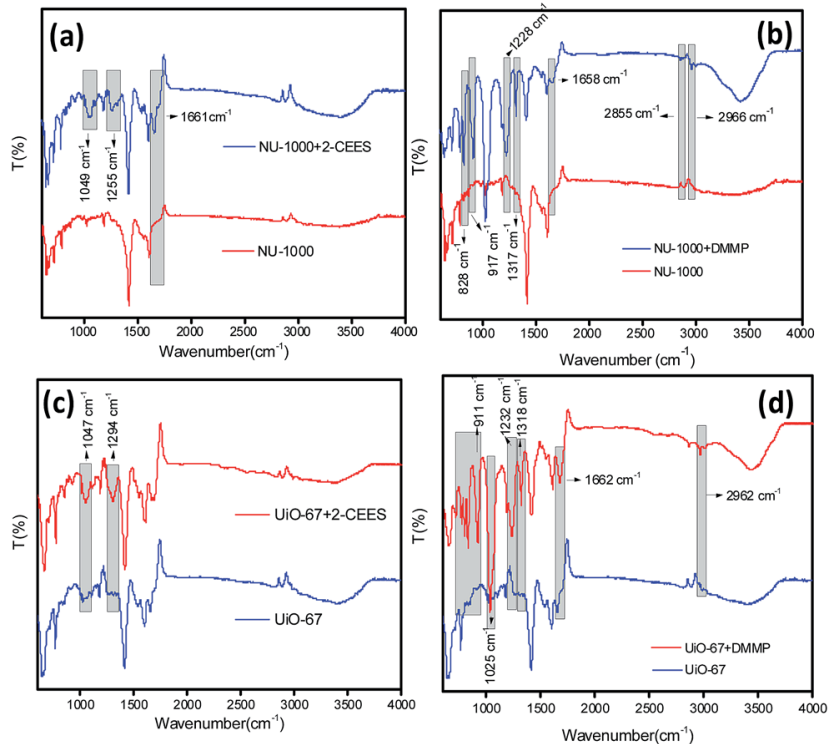

Fig. 2 DRIFT IR spectra for the combinations (a) NU-1000-2-CEES; (b) NU-1000-DMMP; (c) UiO-67-2-CEES and (d) UiO-67-DMMP. the $\mathrm{Zr}-\mathrm{OH}$ nodes significantly decrease the $\mathrm{P}-\mathrm{O}$ stretching frequencies in the DMMP thereby leads to the red-shift of the peaks. ${ }^{61}$

In the case of UiO-67 with 2-CEES, we have observed two new peaks at $1294 \mathrm{~cm}^{-1}$ and $1047 \mathrm{~cm}^{-1}$ which are red-shifted peaks of 2-CEES at $1298 \mathrm{~cm}^{-1}$ and $1058 \mathrm{~cm}^{-1}$, respectively (Fig. 2c). Coming to the combination of UiO-67 with DMMP, a number of new peaks could be seen at $2962 \mathrm{~cm}^{-1}, 1662 \mathrm{~cm}^{-1}, 1318 \mathrm{~cm}^{-1}$, $1232 \mathrm{~cm}^{-1}, 1025 \mathrm{~cm}^{-1}, 911 \mathrm{~cm}^{-1}, 819 \mathrm{~cm}^{-1}$ and $790 \mathrm{~cm}^{-1}$. While the peaks at $2962 \mathrm{~cm}^{-1}, 1318 \mathrm{~cm}^{-1}, 1232 \mathrm{~cm}^{-1}, 1025$ $\mathrm{cm}^{-1}, 911 \mathrm{~cm}^{-1}, 819 \mathrm{~cm}^{-1}$ and $790 \mathrm{~cm}^{-1}$ are red-shifted peaks of the corresponding peaks at $2974 \mathrm{~cm}^{-1}, 1318 \mathrm{~cm}^{-1}, 1246$ $\mathrm{cm}^{-1}, 1043 \mathrm{~cm}^{-1}, 920 \mathrm{~cm}^{-1}, 829 \mathrm{~cm}^{-1}$ and $802 \mathrm{~cm}^{-1}$, respectively, in the pure DMMP IR spectra (Fig. 2d).

\section{Adsorption study monitored by ICP-AES data}

From the ICP-AES results it is evident that the NU-1000 is better compared to UiO-67 and we have used the data for kinetic modeling for the same (Table S1†). Control experiments without the MOFs were also carried out, and it showed negligible change in concentration of the microelements (Table S1 $\dagger$ ). The sorption percentage $(E)$ and sorption capacity $(q)$ of the simulants were defined by the equations

$$
\begin{gathered}
E(\%)=\frac{\left(C-C_{\text {eq. }}\right)}{C} \times 100 \\
q=\frac{\left(C-C_{\text {eq. }}\right)}{m} \times v
\end{gathered}
$$

where, $C$ and $C_{\text {eq. }}$ are the concentrations of the adsorbates in the aqueous solution in ppm at the initial time and equilibrium respectively, $m$ is the mass of the adsorbent in $\mathrm{kg}$ and $v$ is the volume of adsorbate solution used for the studies in $\mathrm{mL}$. These are in the order of $4.197 \mathrm{mmol} \mathrm{g}^{-1}$ and $4.00 \mathrm{mmol} \mathrm{g}^{-1}$ by NU1000 and UiO-67, respectively, for 2-CEES and/or C. Whereas DMMP adsorption were $1.70 \mathrm{mmol} \mathrm{g}^{-1}\left(211.44 \mathrm{mg} \mathrm{g}^{-1}\right)$ and $0.90 \mathrm{mmol} \mathrm{g}^{-1}\left(112.2 \mathrm{mg} \mathrm{g}^{-1}\right)$ by NU-1000 and UiO-67, respectively.

\section{Sorption kinetics}

The rate of adsorption of 2-CEES and/or the hydrolysis products(C) on NU-1000 is studied with an initial concentration of $9.879 \mathrm{mmol} \mathrm{L}^{-1}$ of the simulant (Fig. S16†). Initially, adsorption took place very fast and reached equilibrium at around $210 \mathrm{~min}$, and after that, there was no much change in the concentration of simulant. The initial rapid removal of 2-CEES and/or C could be due to the availability of plenty of vacant active sites in the MOF structure, where 2-CEES and/or C may be adsorbed. After that, the availability of vacant sites was less due to the partial blockage by the captured 2-CEES and/or C molecules, resulting in a gradual decrease in adsorption.

The amount of 2-CEES and/or C adsorbed on the MOF as a function of time were simulated using a pseudo-first order model and pseudo-second order model (Fig. S17 \& S18 †).

Pseudo-first order equation is given by 
Table 1 Kinetic parameters of pseudo-first-order, pseudo-second-order and Weber-Morris models for the adsorption of 2-CEES and/or $\mathrm{C}$ on $\mathrm{NU}-1000\left(C_{\text {initial }}=9.879 \mathrm{mmol} \mathrm{L}^{-1}, \mathrm{NU}-1000=0.03 \mathrm{~g} \mathrm{~L}^{-1}, T=25^{\circ} \mathrm{C}, \mathrm{pH}=7\right)$

\begin{tabular}{|c|c|c|c|c|c|c|c|c|}
\hline \multicolumn{3}{|c|}{ Pseudo-first-order } & \multicolumn{3}{|c|}{ Pseudo-second-order } & \multicolumn{3}{|c|}{ Intraparticle diffusion model } \\
\hline$k_{1}\left(\min ^{-1}\right)$ & $q_{\mathrm{e}}\left(\mathrm{mmol} \mathrm{g}^{-1}\right)$ & $R^{2}$ & $k_{2}\left(\min ^{-1}\right)$ & $q_{\mathrm{e}}\left(\mathrm{mmol} \mathrm{g}^{-1}\right)$ & $R^{2}$ & $k_{\text {id }}\left(\min ^{-1}\right)$ & $I$ & $R^{2}$ \\
\hline $6.5 \times 10^{-4}$ & 1.03 & 0.68 & 0.005 & 4.32 & 0.99 & 0.07 & 3.27 & 0.70 \\
\hline
\end{tabular}

$$
\log \left(q_{\mathrm{e}}-q_{t}\right)=\log q_{\mathrm{e}}-\frac{k_{1}}{2.303} \times t
$$

where $q_{\mathrm{e}}$ and $q_{t}$ are the amounts of 2-CEES and/or $\mathrm{C}$ adsorbed by NU-1000 at equilibrium and at the time, $t$, respectively. $k_{1}$ is the pseudo-first order rate constant $\left(\min ^{-1}\right)$. On plotting $\log \left(q_{\mathrm{e}}-q_{t}\right)$ with respect to time $(t)$ gives a straight line and its slope gives the value of $k_{1}$.

For the pseudo-second order model, the equation used is

$$
\begin{gathered}
\frac{t}{q_{t}}=\frac{1}{k_{2} q_{\mathrm{e}}^{2}}+\frac{t}{q_{\mathrm{e}}}(\text { type I }) \\
q_{\mathrm{e}}=\frac{1}{\text { slope }} ; \quad k_{2}=\frac{(\text { slope })^{2}}{\text { intercept }}
\end{gathered}
$$

$q_{\mathrm{e}}$ and $q_{t}$ are the same as above, $k_{2}$ is the pseudo-second order rate constant $\left(\mathrm{g} \mathrm{mg}^{-1} \mathrm{~min}^{-1}\right)$. A plot of $t / q_{t}$ as a function of time $(t)$ gives a linear plot. The values of $q_{\mathrm{e}}$ and $k_{2}$ can be calculated from the slope and intercept of the straight line.

Pseudo-second order model with the correlation coefficient equal to 0.9973 is more appropriate in explaining the process of adsorption of 2-CEES and/or C on NU-1000. The value of $q_{\mathrm{e}}$, $4.32 \mathrm{mmol} \mathrm{g}^{-1}$ also agrees with the experimental value of $4.197 \mathrm{mmol} \mathrm{g}^{-1}$. Better fitting was done with pseudo-secondorder model by assuming that the rate determining step would be the valence forces through sharing or exchange of electrons between adsorbate and adsorbent. ${ }^{54}$ Moreover, the adsorption with chelating ligands mostly follows pseudosecond-order kinetics. ${ }^{55}$ Here the mesoporous structure and the functional groups on NU-1000 make it act as a chelating agent thereby following the pseudo-second-order kinetics. Since adsorption follows pseudo-second-order model, the force of attraction is assumed to be chemical in nature. ${ }^{\mathbf{5 2 , 5 3}}$

The nature of interaction can be clearly explained by considering the porous nature of the MOF. At first, there exist some active sites which attract the 2-CEES and/or C molecules in the solution. After a monomolecular layer is formed, the other 2-CEES and/or C molecules present in the solution pushes the already adsorbed molecules to the interior of the framework since it is sufficiently porous. There are two types of interactions in the case of 2-CEES adsorbed onto NU-1000, the weak polar interaction of $\mathrm{S}^{2-}$ with the $\mathrm{Zr}^{4+}$ ions in the metal nodes, which could be considered as a weak physical force of attraction. ${ }^{43}$ Then, the hydrogen bond between the hydroxyl groups in the metal nodes and the elements, chlorine and sulfur of 2-CEES and/or $\mathrm{C}$ which may be responsible for intra-particle diffusion and further binding of the adsorbate. ${ }^{43-45,56-60}$ The carboxylic group of the TBAPy ligand also adds to the strength of hydrogen bonding. Hence, the result of the various interactions between the 2-CEES and/or C and NU-1000 act as a strong chemical bond. The DRIFTS data evidence these interactions.

To know the effect of intra-particle diffusion in the overall sorption process, we have fitted the data with intra-particle diffusion model (Webber and Morris model).

$$
q_{t}=k_{\mathrm{id}} t^{1 / 2}
$$

where $k_{\mathrm{id}}$ is the intra-particle diffusion constant. A graph between $q_{t}$ vs. $t^{1 / 2}$ gives a straight line which gives the value of $k_{\text {id }}$. Plots of $q_{t}$ vs. $t$ (Fig. S19 $\dagger$ ) can be divided into two linear segments, indicating that diffusion process proceeds via two steps. The initial portion represents the boundary layer diffusion ascribed to the external mass transfer of the adsorbate from the bulk solution to the outer surface of the MOF. The second phase is controlled by intraparticle diffusion of 2-CEES throughout the open cavities of NU-1000 (Table 1). ${ }^{34}$

Kinetic parameters of adsorption of DMMP by NU-1000 are given in Table 2. In this case also pseudo-second order kinetics is followed with the value of $R^{2}$ as 0.999 . It shows that the interactions between DMMP and NU-1000 are also chemical in nature, which was proved by DRIFT spectral data. Weber-Morris model or the intra-particle diffusion model has been tried which is found to be agreeing with the experimental data (Fig. S20-S23†).

Few research groups are working on the detoxification of the chemical warfare agents using MOFs. Among those, Hupp and coworkers have noted contribution in this area. Recently they have identified new $\mathrm{Zr}^{\mathrm{IV}}$-containing MOFs, which can rapidly

\begin{tabular}{|c|c|c|c|c|c|c|c|c|}
\hline \multicolumn{3}{|c|}{ Pseudo-first-order } & \multicolumn{3}{|c|}{ Pseudo-second-order } & \multicolumn{3}{|c|}{ Intraparticle diffusion model } \\
\hline$k_{1}\left(\min ^{-1}\right)$ & $q_{\mathrm{e}}\left(\mathrm{mmol} \mathrm{g}^{-1}\right)$ & $R^{2}$ & $k_{2}\left(\min ^{-1}\right)$ & $q_{\mathrm{e}}\left(\mathrm{mmol} \mathrm{g}^{-1}\right)$ & $R^{2}$ & $k_{\text {id }}\left(\min ^{-1}\right)$ & $I$ & $R^{2}$ \\
\hline $5.8 \times 10^{-4}$ & 1.32 & 0.89 & $9.38 \times 10^{-3}$ & 4.41 & 0.99 & 0.07 & 2.74 & 0.96 \\
\hline
\end{tabular}
capture simulants of organophosphorus nerve agents, mustard

Table 2 Kinetic parameters of pseudo-first-order, pseudo-second-order and Weber-Morris models for DMMP on NU-1000 $\left(C_{\text {initial }}=9.8\right.$ mmol $\left.\mathrm{L}^{-1}, \mathrm{NU}-1000=0.03 \mathrm{~g} \mathrm{~L}^{-1}, T=25^{\circ} \mathrm{C}, \mathrm{pH}=7\right)$ 
gas as well as the CWA soman. ${ }^{31 b, 33,39,40}$ Navarro and coworkers were developed advanced self-detoxifying adsorbents by doping lithium alkoxide with $\mathrm{Zr}^{\mathrm{IV}}$ MOF for the hydrolytic degradation of DMMP. ${ }^{14}$ They also integrated this into self-detoxifying protective fabrics which combine air permeation and self-detoxifying properties. Gu and coworkers recently have shown that Zr-based MOF can be used for efficient adsorption and enhanced removal of organophosphorus pesticides. ${ }^{34}$ Most of these cases MOFs have been utilized for the hydrolytic cleavage of the toxic CWAs. Report on adsorptive removal and their kinetic study is very rare. ${ }^{34}$ Here we have shown these two MOFs can be used for the adsorption of 2-CEES and DMMP from aqueous medium efficiently and NU1000 can be recycled. Detailed kinetics study has demonstrated the interactions between the MOFs, and CWAs are chemical in nature and follow the pseudo-second-order model.

\section{Conclusions}

In conclusion, the zirconium-based metal-organic frameworks NU-1000 and UiO-67 are successfully used for the adsorptive removal of the chemical warfare agent simulants 2-CEES and/or its hydrolysis products and DMMP from the aqueous medium. NU-1000 is showing outstanding performance in the case of both efficiency and reusability for the adsorption of the simulants from the aqueous medium. This MOF exhibits adsorptive capacities in the order of, 4.197 and $1.70 \mathrm{mmol} \mathrm{g}^{-1}$ for 2-CEES and/or $\mathrm{C}$ and DMMP, respectively. NU-1000 is recyclable up to 3 cycles. We have compared these results with UiO-67, and the results are showing that it can also adsorb 2-CEES and DMMP (4.000 and $0.90 \mathrm{mmol}$ $\mathrm{g}^{-1}$, respectively), but less efficiently than NU-1000.

The adsorption kinetics of the simulants by NU-1000 is studied by exploiting the timely adsorption data from ICP-AES measurements. It is found that the adsorption follows pseudo-second-order kinetics in both the cases and hence gives the evidence of chemical interactions between the NU-1000 and the CWA simulants. The DRIFT spectral data supported the existence of chemical interactions. These chemical interactions might be due to the hydrogen bond between the thioether and chloro groups of 2-CEES with the $\mathrm{Zr}-\mathrm{OH}$ groups at the nodes of the MOFs. The affinity of the zirconium nodes for the phosphate groups may be responsible for DMMP to bind to the MOF structure strongly. This structureproperty correlation may find a new direction to design the efficient adsorbents for the effective removal of toxic chemicals.

\section{Acknowledgements}

We acknowledge financial support from Science and Engineering Research Board (SERB), Govt. of India, through a grant SB/S1/IC-14/2013. We acknowledge SAIF, IIT Bombay for the ICP-AES data. We thank Prof. V. Ramakrishnan for encouragement. PA acknowledges CSIR for JRF.

\section{References}

1 S. Chauhan, S. Chauhan, R. D'Cruz, S. Faruqi, K. K. Singh, S. Varma, M. Singh and V. Karthik, Environ. Toxicol. Pharmacol., 2008, 26, 113.
2 S. S. Talmage, A. P. Watson, V. Hauschild, N. B. Munro and J. King, Curr. Org. Chem., 2007, 11, 285.

3 M. W. Ma and D. H. Kuo, J. Hazard. Mater., 2016, 301, 84.

4 R. A. Bennett, E. Behrens, A. Zinn, C. Duncheon and T. J. Lamkin, Cell Biol. Toxicol., 2014, 30, 195.

5 (a) L. A. Patil, V. V. Deo, M. D. Shinde, A. R. Bari and M. P. Kaushik, Sens. Actuators, B, 2011, 160, 234; (b) L. A. Patil, V. V. Deo, M. D. Shinde, A. R. Bari, D. M. Patil and M. P. Kaushik, Sens. Actuators, B, 2014, 191, 130.

6 (a) V. Kumar and E. V. Anslyn, J. Am. Chem. Soc., 2013, 135, 6338; (b) M. C. Horrillo, J. Martía, D. Matatagui, J. P. Santos, I. Sayago, J. Gutiérrez, I. Martin-Fernandez, P. Ivanov, I. Gràcia and C. Canéb, Sens. Actuators, B, 2011, 157, 253.

7 L. A. Patil, V. V. Deo, M. D. Shinde, A. R. Bari, D. M. Patil and M. P. Kaushik, Sens. Actuators, B, 2011, 160, 234.

8 A. A. Tomchenko, G. P. Harmer and B. T. Marquis, Sens. Actuators, B, 2005, 108, 41.

9 M. L. Ramírez-Cedeño, W. Ortiz-Rivera, L. C. PachecoLondoño and S. P. Hernández-Rivera, IEEE Sens. J., 2010, 10, 693.

10 A. A. Vernekar, T. Das and G. Mugesh, Angew. Chem., Int. Ed., 2016, 55, 1412.

11 D. A. Giannakoudakis, J. K. Mitchella and T. J. Bandosz, J. Mater. Chem. A, 2016, 4, 1008.

12 Y. Liu, A. J. Howarth, J. T. Hupp and O. K. Farha, Angew. Chem., Int. Ed., 2015, 54, 9001.

13 M. Verma, R. Chandra and V. K. Gupta, J. Colloid Interface Sci., 2015, 453, 60.

14 E. Lopez-Maya, C. Montoro, L. M. Rodriguez-Albelo, S. D. A. Cervantes, A. A. Lozano-Perez, J. L. Cenis, E. Barea and J. A. R. Navarro, Angew. Chem., Int. Ed., 2015, 54, 6790.

15 D. A. Chen, J. S. Ratliff, X. Hua, W. O. Gordon, S. D. Senanayake and D. R. Mullins, Surf. Sci., 2010, 604, 574.

16 D. A. Trubitsyn and A. V. Vorontsov, Mendeleev Commun., 2004, 14, 195.

17 J. R. Hiscock, M. R. Sambrook, N. J. Wellsa and P. A. Gale, Chem. Sci., 2015, 6, 5680.

18 F.-J. Ma, S.-X. Liu, C.-Y. Sun, D.-D. Liang, G.-J. Ren, F. Wei, Y.-G. Chen and Z.-M. Su, J. Am. Chem. Soc., 2011, 133, 4178.

19 M. B. Mitchell, V. N. Sheinker and E. A. Mintz, J. Phys. Chem. B, 1997, 101, 11192.

20 K. Knagge, M. Johnson, V. H. Grassian and S. C. Larsen, Langmuir, 2006, 22, 11077.

21 J. Quenneville and R. S. Taylor, J. Phys. Chem. C, 2010, 114, 18894.

22 D. A. Trubitsyn and A. V. Vorontsov, J. Phys. Chem. B, 2005, 109, 21884.

23 E. A. Kozlova, P. G. Smirniotis and A. V. Vorontsov, J. Photochem. Photobiol., A, 2004, 162, 503.

24 E. Barea, C. Montoro and J. A. R. Navarro, Chem. Soc. Rev., 2014, 43, 5419.

25 D. A. Panayotov, D. K. Paul and J. T. Yates Jr, J. Phys. Chem. B, 2003, 107, 10571.

26 B. Sun, A. V. Vorontsov and P. G. Smirniotis, J. Hazard. Mater., 2011, 186, 1147. 
27 (a) Y. Liu, A. J. Howarth, J. T. Hupp and O. K. Farha, Angew. Chem., Int. Ed., 2015, 54, 9001; (b) G. W. Peterson, S. Y. Moon, G. W. Wagner, M. G. Hall, J. B. DeCoste, J. T. Hupp and O. K. Farha, Inorg. Chem., 2015, 54, 9684.

28 Y. Liu, S. Y. Moon, J. T. Hupp and O. K. Farha, ACS Nano, 2015, 9, 12358.

29 E. M. Dias and C. Petit, J. Mater. Chem. A, 2015, 3, 22484.

30 J. Cavka, S. Jakobsen, U. Olsbye, N. Guillou, C. Lamberti, S. Bordiga and K. Petter Lillerud, J. Am. Chem. Soc., 2008, 130, 13850.

31 (a) M. M. Benning, J. M. Kuo, F. M. Raushel and H. M. Holden, Biochemistry, 1994, 33, 15001; (b) M. J. Katz, J. E. Mondloch, R. K. Totten, J. K. Park, S. T. Nguyen, O. K. Farha and J. T. Hupp, Angew. Chem., Int. Ed., 2014, 53, 497.

32 (a) A. N. Bigley and F. M. Raushel, Biochim. Biophys. Acta, Gen. Subj., 2013, 1834, 443; (b) K.-Y. Wong and J. Gao, Biochemistry, 2007, 46, 13352.

33 S. Y. Moon, Y. Liu, J. T. Hupp and O. K. Farha, Angew. Chem., Int. Ed., 2015, 54, 6795.

34 X. Zhu, B. Li, J. Yang, Y. Li, W. Zhao, J. Shi and J. Gu, ACS Appl. Mater. Interfaces, 2015, 7, 223.

35 S. S. Mondal and H. J. Holdt, Angew. Chem., Int. Ed., 2016, 55, 42.

36 S. Y. Bae and M. D. Winemiller, J. Org. Chem., 2013, 78, 6457. 37 Y. C. Yang, L. L. Szafraniec, W. T. Beaudry and J. R. Wa, J. Org. Chem., 1988, 53, 3293.

38 M. J. Katz, S. Y. Moon, J. E. Mondloch, M. H. Beyzavi, C. J. Stephenson, J. T. Hupp and O. K. Farha, Chem. Sci., 2015, 6, 2286.

39 J. E. Mondloch, M. J. Katz, W. C. Isley, P. Ghosh, P. Liao, W. Bury, G. W. Wagner, M. G. Hall, J. B. DeCoste, G. W. Peterson, R. Q. Snurr, C. J. Cramer, J. T. Hupp and O. K. Farha, Nat. Mater., 2015, 14, 512.

40 P. Li, R. C. Klet, S. Moon, T. C. Wang, P. Deria, A. W. Peters, B. M. Klahr, H. J. Park, S. S. Al-Juaid, J. T. Hupp and O. K. Farha, Chem. Commun., 2015, 51, 10925.

41 (a) G. W. Peterson, S. Y. Moon, G. W. Wagner, M. G. Hall, J. B. DeCoste, J. T. Hupp and O. K. Farha, Inorg. Chem., 2015, 54, 9684; (b) T. J. Daou, S. Begin-Colin, J. M. Grenèche, F. Thomas, A. Derory, P. Bernhardt, P. Legaré and G. Pourroy, Chem. Mater., 2007, 19, 4494.

42 S. Y. Moon, G. W. Wagner, J. E. Mondloch, G. W. Peterson, J. B. De Coste, J. T. Hupp and O. K. Farha, Inorg. Chem., 2015, 54, 10829.

43 (a) H. Furukawa, F. Gaándara, Y. Zhang, J. Jiang, W. L. Queen, M. R. Hudson and O. M. Yaghi, J. Am. Chem.
Soc., 2014, 136, 4369; (b) J. A. Arcibar-Orozco, S. Panettieri and T. J. Bandosz, J. Mater. Chem. A, 2015, 3, 17080; (c) D. B. Mawhinney, J. A. Rossin, K. Gerhart and J. T. Yates, Langmuir, 1999, 15, 4789; (d) D. Panayotov and J. T. Yates, J. Phys. Chem. B, 2003, 107, 10560.

44 A. J. Howarth, M. J. Katz, T. C. Wang, A. E. Platero-Prats, K. W Chapman, J. T. Hupp and O. K. Farha, J. Am. Chem. Soc., 2015, 137, 7488.

45 E. D. Davis, W. O. Gordon, A. R. Wilmsmeyer, D. Troya and J. R. Morris, J. Phys. Chem. Lett., 2014, 5, 1393.

46 E. J. Park and Y. D. Kim, Bull. Korean Chem. Soc., 2013, 34, 1967.

47 J. Abelard, A. R. Wilmsmeyer, A. C. Edwards, W. O. Gordon, E. M. Durke, C. J. Karwacki, D. Troya and J. R. Morris, J. Phys. Chem. C, 2015, 119, 365.

48 P. Canepa, N. Nijem, Y. J. Chabal and T. Thonhauser, Phys. Rev. Lett., 2013, 110, 026102.

49 A. J. Howarth, T. C. Wang, S. S. Al-Juaid, S. G. Aziz, J. T. Hupp and O. K. Farha, Dalton Trans., 2016, 45, 93.

50 K. C. Stylianou, R. Heck, S. Y. Chong, J. Bacsa, J. T. A. Jones, Y. Z. Khimyak, D. Bradshaw and M. J. Rosseinsky, J. Am. Chem. Soc., 2010, 132, 4119.

51 T. C. Wang, N. A. Vermeulen, I. S. Kim, A. B. Martinson, J. F. Stoddart, J. T. Hupp and O. K. Farha, Nat. Protoc., 2016, 11, 149.

52 H. Fei and S. M. Cohen, Chem. Commun., 2014, 50, 4810.

53 M. J. Katz, Z. J. Brown, Y. J. Colón, P. W. Siu, K. A. Scheidt, R. Q. Snurr, J. T. Hupp and O. K. Farha, Chem. Commun., 2013, 49, 9449.

54 Y. S. Ho and G. McKay, Process Biochem., 1999, 34, 451.

55 C. Kantipijly, S. Katragadda, A. Chow and H. D. Gesser, Talanta, 1990, 37, 491.

56 Y. S. Ho and G. McKay, Water Res., 2000, 34, 735.

57 H. S. Biswal and S. Wategaonkar, J. Phys. Chem. A, 2009, 113, 12774.

58 G. Nickerl, M. Leistner, S. Helten, V. Bon, I. Senkovskaa and S. Kaskel, Inorg. Chem. Front., 2014, 1, 325.

59 A. A. Lizzio and J. A. DeBarr, Energy Fuels, 1997, 11, 284.

60 D. A. Giannakoudakis and T. J. Bandosz, J. Colloid Interface Sci., 2014, 436, 296.

61 A. Mattsson, C. Lejon, V. Stengl, S. Bakardjieva, F. Opluštil, P. O. Andersson and L. Österlund, Appl. Catal., B, 2009, 92, 401.

62 T. J. Daou, S. Begin-Colin, J. M. Grenèche, F. Thomas, A. Derory, P. Bernhardt, P. Legaré and G. Pourroy, Chem. Mater., 2007, 19, 4494. 